\title{
The implications of Pricing to Market based Based on whether Whether Purchasing Power Parity holding Holding in China
}

\author{
Xinzhan Liu, ${ }^{1, a}$, Bin Tang ${ }^{2, b}$ \\ ${ }^{1}$ Xi'an Peihua University, Xi'an City, Shaan'xi Province, China \\ ${ }^{2}$ Center for Experimental Economics in Education (CEEE), Shaanxi Normal \\ University, Xi'an, China \\ a 2223564807@qq.com \\ b tangbin198994@163.com
}

Keywords: Pricing to market, Purchasing power parity, China.

\begin{abstract}
This paper summarizes the results of Pricing to Market (PTM) and whether purchasing power parity(PPP) theory is established under PTM and takes China as an example for analysis. The impact may vary from country to country, depending on the degree to which PTM and purchasing power parity are held. In terms of specific circumstances, China, with a relatively strong PTM, will not experience frequent exchange rate fluctuations and is expected to improve its market mechanism and optimize the welfare of all business participants with PPP holding in China. However, how to use empirical data to measure the degree of PTM remains to be focus of the next stage.
\end{abstract}

\section{Introduction}

Pricing to Market (PTM), an elusive kind of Price Discrimination, has shown an unerring knack for attracting economists' attention, as it is bound up with Purchasing Power Parity (PPP). Empirically, connotation of PTM may vary hinging on whether PPP holds in a certain economy. China, remarkably, has ranked the head of the world's largest trading power, creditor and market for commodities since 2012 (Bloomberg News, 2013). This essay aims to summarise and refine the implications of PTM on ground of PPP dimension and to examine the specific circumstances in an applied economy (selecting China as the representative). It has been well-organised with the following structure: first, overviews and discussion of PM on the basis of PPP will be critically synthesised and presented; and then, this paper will examine whether PPP could be employed to account for China's exchange rate regime; finally, the specific implications of PTM in China will be explored reasonably.

\section{Overviews on Pricing to Market towards Purchasing Power Parity}

\subsection{Concept of Pricing to Market}

It is apparent that, based on economic observations, real exchange rates exhibit great and significant deviations from Purchasing Power Parity (PPP) (Bettsa and Devereux, 1996). Numerous studies have identified Pricing to Market (PTM), along with productivity shocks has led an overriding role in the fluctuations of exchange rates and nominal price stickiness (Bettsa and Devereux, 2000). PTM, stemming from the marketing pricing area, has been regarded as identical to third-degree price discrimination, that is, "firms tend to set prices in local currencies of sale, and do not adjust prices to movements in the exchange rate"(Bettsa and Devereux, 1996, p1008). The study with great contributions made by Engel and Rogers (1996) finds that both geographical distance and border are momentous determinants explaining the volatility of relative prices, accounting for 19\% and 33\% respectively. The border discrepancy primarily is derived from PTM charaterised by two basic features: effectively segmenting markets in various capacities and steadily showing "local currency price stability" (Bettsa and Devereux, 1996, p1008). Market segmentation requires to large 
extent pricing of products with different qualities has the capacity of being applied and implemented in relatively separated areas; otherwise, arbitragers could achieve profits through selling or buying homogeneous products across countries. In addition, PTM is closely related to sticky prices, together generating unified results of interest (Krugman,1986) and local sticky CPI prices demonstrate more responsiveness to money shocks(Bettsa and Devereux, 2000).

\subsection{Implications of PTM on PPP holding or not}

By virtue of market segmentation and stable price-setting, PTM reveals abundant implication and variations towards the validity of PPP in relevant regions, which has been verified and acknowledged by countless studies (such as Aizenman(2004); Aoki(2007); Gourinchas and Tornell (2004) ). The overall implications of PTM could be examined from three perspectives.

First, it is the nominal price stickiness linked with PTM that enlarges the effects of exchange rate fluctuations towards money shocks, with respect to cases where PPP holds. When local prices of products are sticky, the existence of PTM has implications for exchange rate volatility that diverge considerably from those triggered by a flexible price model (Aizenman, 2004) or by a sticky-price partial equilibrium model in which PTM is not happening around. Once firms are bound up in PTM, country specific money shocks exhibit far greater variability in modeling research. On the other hand, without PPP assumption, an exchange rate appreciation or depreciation will pose little effect on relative prices of imported products targeting at domestic consumers (Crucini and Shintani, 2008). Hence, the allocated function of exchange rate adjustment is weak prominently confined by PTM and thereby the vacillation of exchange rate is much more tempestuous.

The extent of PTM, moreover, has sort of proportional relationships with comovement between consumption and production. Without PTM, economic disturbances are inclined to bring about significant positive comovements of consumption across countries, but large negative comovements of yield (Bettsa and Devereux, 2000). However, it is totally different that considering the presence of PTM, consumption comovement is bound to decrease on account of departures from one price law. In this sense, the substitution of expenditures weakening and exerting little effect drives a dramatic and continuous augment of output comovement, which is in conjunction with the findings that "observed low cross country consumption correlation and high output correlations are anomalous when compared to the predictions of models based on PPP" ( Bettsa and Devereux, 2000, p218).

Additionally, the implication is exceedingly profound and crucial on welfare. On the basis of PPP theory, "an unanticipated monetary expansion" (Bettsa and Devereux, 2000, p218) benefits proxy including import and export traders. If there is PTM inherent in an economy, the domestic monetary expansion give priority to increasing domestic welfare, accordingly declining foreign benefits, just as Bettsa and Devereux (2000, p218) maintain "monetary policy is a beggar-thy-neighbor instrument in the presence of PTM", which therefore indicates the dynamic implications for international monetary policy adoption are totally distinguished compared with the situation of PTM linked with PPP.

Finally, market segmentation, in existence of PTM, also correlates with PPP holding. If PPP regime applies in an economy, namely domestic currency and foreign currency are exchanged and aggregated, the boundary of individual markets will be less distinct and the chances of arbitrage will be relatively possible allowing for the decisions made by firms in the light of PPP. Without PPP, discriminate prices are easily carried out for the correlation lacks standards and mechanism of interaction. Allowing for the trade cost including transportation cost, distribution costs (Atkeson and Burstein, 2008), policy differentials and cultural factors, residents' conventional preference and the independence of institutional regimes, complete PTM displays a more flexible, fickle but home-made tendency.

\section{Does PPP hold in China?}

Whether PPP holds in specific countries or not has been a long-suffering and abstruse problem having captured a large number of researchers and involved various techniques employed to 
observe and analysed. Most empirical works have confirmed that PPP exhibits vulnerable explanations for exchange rate behaviours in the short run whereas long-run data provides a reasonably decent description to partial equilibrium on PPP(Taylor, 2001; George and Kaboski, 2011). Consensus has been reached and embodied in OECD countries that PPP holds significantly across long periods of experiencing systematic transformation(Okano, 2007). It is, nevertheless, not the case in many developing countries (Carrieri and Majerbi, 2006).

Though China, struggling through over 30 years' reform and adjustment in openness, has achieved remarkably surprising economic performance and leapt to be the largest trade economy of the world, it still remains to be a developing country and controversies on PPP holding or not have never stopped(Deng and Sun, 2007). This paper carefully compared and examined literature regarding the response to PPP in China, aiming at discussing the implication of PTM in China well-grounded and comprehensively.

Numerous methods have been adopted to measure PPP holding in Asian economies including China ranging from the earliest OLS regression(Gourinchas and Tornell, 2004), unit-root and co-integration tests (Bec,et al.2004), to the approaches to long-term data and panel data(Crucini and Shintani, 2008; Sun, 2007) and till the recent non-linear framework(Feng, 2011). Feng (2011) applies KPSS tests based on the non-linear ESTAR model to test the long-term PPP in China, Korea and Japan during the period of 1949 to 2009. The regression is $\Delta y_{t}=\delta y_{t-1}^{3}+u_{t}$, Figure 1 and 2 shows that the exchange rate in China accords with PPP. However, Zheng (2010) first uses conventional ADF test, and then employs DF-GLS test, constructs $\operatorname{AR~}(\rho)$ model $Y_{t}=\rho_{t} Y_{t-1}+\rho_{2} Y_{t-2}+\cdots+\rho_{\rho} Y_{t-\rho}+\varepsilon_{t}$ for real exchange rate of Chinese RMB and Korean won and computes half-life of shocks to the real exchange rate (Figure 3, Figure 4 and Figure 5), finding that China did not hold PPP from 1978 to 2008. Xu (2007) discovers that the shift from lower regime to higher regime in Chinese exchange rate is fast and smooth and PPP does not hold despite intensive international connections and rapid trade volume.

Some rigorous empirical analyses have manifested the failure of PPP in China which can be chiefly explained for some characteristic reasons. Like discussed above, the physical existence of trade barrier and transaction cost contradicts with one price law laying a solid foundation for PTM in China and vice versa, PTM magnifies the fluctuations of exchange rate diverging from PPP. Interestingly, China was a central-planned economy without any market efficient benefits before 1978 and still possesses a rigid governmental control and regulation on exchange rate, which contributes greatly to the formation of Chinese RMB exchange rate regime and causes the particular imbalance of import and export.

\section{Implications of PTM in China without PPP holding}

With advanced econometric techniques, the view that China as a typical and conspicuous country defines little PPP holding has been corroborated. In terms of the circumstances of China, the sweeping implications may vary and some specific underlying meaning could be captured.

First, on no condition of PPP holding, the pre-setting prices in China could be more stable and distinguished from those in other subdivision markets although the variability of exchange rate would be sharper and more vulnerable theoretically. Actually, nonetheless, allowing for Chinese institutional control, prudent currency management and local conservative consuming characteristics, China might not witness the pitfalls of intense shocks and experience frequent volatility(Wang, 2012).

Furthermore, PTM presents the strong monopoly power and imperfection of market. More than $70 \%$ of the top 100 Chinese multinational companies are state-owned enterprises, which implies goods trading, producing, circulating and selling is not as flexible as other countries with market liberalization and exposes strong monopoly. Due to lack of sufficient competition, it will never be difficult to give rise to lower output and higher prices that would be potentially detrimental to economic growth. Therefore, buyers' welfare might be seized by sellers more or less and private sector has no incentive to operate. 
Thirdly, the PPP holding hypotheses and testing reveals a favourable exploration of formation of RMB exchange rate mechanism (Liang, 2010), which is quite useful for Chinese government to judge RMB appreciation or depreciation.

\section{Conclusion}

In summary, this essay has outlined PTM results and implications on whether PPP holds or not, and selected China as an example to apply these implications. Implications may vary country by country depending on the extent of PTM and PPP holding. China, with a relatively strong PTM regarding specific circumstances, would not experience frequent fluctuations of exchange rates and is expected to perfect its market mechanism and to optimize welfare benefits of all participants in commerce. However, how to measure the extent of PTM with empirical data remains to be the focus of next stage.

\section{References}

[1] Liang Y. M. (2016). Pricing-to-market and Staggered Pricing. Journal of Regional Financial Research, 451(7), pp.38-42.

[2] Xu G. X.(2017). The empirical study on the purchasing power parity of Chinese RMB's real exchange rate. Ph. D. Hua Zhong University of Science and Technology.

[3] Chen, L. Z., Hu, W. M., Szulga, R., \& Zhou, X. (2018). Demographics, gender and local knowledge-Price discrimination in China's car market. Economics Letters, 163, 172-174.

[4] Kakwani, N., \& Son, H. H. (2016). Global poverty estimates based on 2011 purchasing power parity: where should the new poverty line be drawn?. The Journal of Economic Inequality, 14(2), 173-184.

[5] Gafarova, G., Perekhozhuk, O., \& Glauben, T. (2015). Price discrimination and pricing-to-market behavior of Black Sea region wheat exporters. Journal of Agricultural and Applied Economics, 47(3), 287-316. 